\title{
Non-Hodgkin's lymphoma in childhood: clinical and epidemiological characteristics and survival analysis at a single center in Northeast Brazil
}

\author{
Márcia Ferreira Pedrosa, ${ }^{1}$ Francisco Pedrosa, ${ }^{2}$ Mecneide M. Lins, ${ }^{3}$ \\ Nicodemos T. Pontes Neto, ${ }^{4}$ Gilliatt Hanois Falbo ${ }^{5}$
}

\begin{abstract}
Objective: To describe the clinical and demographic characteristics of non-Hodgkin's lymphoma patients diagnosed at the Pediatric Oncology Unit at the Instituto Materno-Infantil Professor Fernando Figueira (IMIP) over a 9-year period, and also to describe their survival rates and possible associations between the survival rates and the clinical and demographic characteristics analyzed in the study.
\end{abstract}

Methods: This was a cross-sectional study. Data were collected by a retrospective review of the charts of all 110 patients admitted to our unit during the period of May 1994 through May 2003. Probability of survival was calculated in accordance with the techniques of Kaplan-Meier, using log rank to evaluate differences between the groups.

Results: The average age was 6.1 years. The male/female ratio was $2.4: 1$. The most frequent histological subtype was Burkitt's lymphoma. The majority of patients had been diagnosed with advanced disease (stage III or IV of Murphy's Classification) and was from rural areas. Family income per capita was lower than $1 / 2$ minimum wage in $36.4 \%$ of cases; maternal illiteracy was observed in $12.7 \%$ of cases. The 5 -year overall survival and disease-free survival rates were $70 \pm 4 \%$ and $68.4 \pm 4 \%$, respectively. None of the clinical-demographic characteristics had a significant association with the probability of survival $(p>0.05)$.

Conclusion: Children admitted to the IMIP seemed to be affected by non-Hodgkin lymphoma at a younger age, with a higher incidence of Burkitt's lymphoma and with survival rates similar to those described in the literature of developed countries. No clinical demographic characteristics had a statistically significant association with prognosis.

J Pediatr (Rio J). 2007;83(6):547-554: Lymphoma, childhood, epidemiology, cancer, survival, developing countries.

\section{Introduction}

Although rare in childhood, lymphoma among children and adolescents has been receiving ever-growing attention among researchers, not just because of its growing importance from the epidemiological point of view, but also because of the major advances observed in diagnosis and treatment.

Malignant neoplasms are the second cause of child death in developed countries and the fourth cause of death among children and adolescents in Brazil, and they are the second most frequent cause of death, in our country, in the age range five to 9 years, among whom they are only less common than deaths from external causes. ${ }^{1,2}$

In this context, lymphomas are the third most frequently diagnosed malignant neoplasm among children and adolescents in the age range 0 to 15 years, with $60 \%$ of cases being non-Hodgkin's lymphoma ( $\mathrm{NHL}$ ) and $40 \%$ being Hodgkin lymphomas.

1. Mestre. Oncologista pediatra, Unidade de Oncologia Pediátrica, Instituto Materno-Infantil Professor Fernando Figueira (IMIP), Recife, PE, Brazil.

2. Especialista em Cancerologia Infantil. Diretor médico, Unidade de Oncologia Pediátrica, IMIP, Recife, PE, Brazil.

3. Mestre. Oncologista pediatra, Unidade de Oncologia Pediátrica, IMIP, Recife, PE, Brazil.

4. Médico pediatra.

5. Doutor. Médico cirurgião pediátrico. Coordenador, Curso de Medicina, Escola Pernambucana de Medicina, Recife, PE, Brazil.

No conflicts of interest declared concerning the publication of this article.

Suggested citation: Pedrosa MF, Pedrosa F, Lins MM, Pontes Neto NT, Falbo GH. Non-Hodgkin's lymphoma in childhood: clinical and epidemiological characteristics and survival analysis at a single center in Northeast Brazil. J Pediatr (Rio J). 2007;83(6):547-554.

Manuscript received June 26 2007, accepted for publication Oct 172007.

doi 10.2223/JPED.1726 
Depending on the geographic region being studied, there are important differences in relation to the clinical and epidemiological characteristics of NHLs diagnosed during childhood. ${ }^{3,4}$

In equatorial Africa, the Burkitt histological subtype of $\mathrm{NHL}$ accounts for $50 \%$ of all cancers diagnosed in the pediatric age group and has a high incidence of primary tumors involving the jaw, whereas in the rest of the world, this neoplasm accounts for less than $5 \%$ of pediatric cancers, and abdominal primary tumors are the most common presentation. ${ }^{3,5}$ In the northeast of Brazil, a high frequency of the Burkitt histological subtype has also been reported in the past. ${ }^{6,7}$

Among the prognostic factors of childhood NHL that have been studied, the factor with greatest consensus in the literature is the tumor burden at the time of diagnosis, normally quantified by staging and serum lactate dehydrogenase (LDH) levels. Others important prognostic factors are: the type of treatment and the location where this is carried out, with patients on more modern therapeutic schemes at centers with appropriate experience and infrastructure, exhibiting better survival rates. ${ }^{3}$

Developing countries often have inferior survival rates than developed countries, and this finding is generally related to the low social economic status in these regions, which makes early diagnosis and the use of effective treatments nonviable. ${ }^{8}$

It was the scarcity of existing data in the literature illustrating the behavior of $\mathrm{NHL}$ among the children of our region that induced us to carry out this study, with the intention of describing the clinical, epidemiological and socioeconomic characteristics of our NHL patients, assessing their survival and searching for possible prognostic associations with the variables under analysis.

\section{Methods}

This study included all patients with non-Hodgkin's lymphoma diagnosed at the Pediatric Oncology Unit at the Instituto Materno-Infantil Professor Fernando Figueira (IMIP) during its first 9 years of operations, from May, 1994 to May, 2003. Only one patient was excluded due to the fact that their data were not sufficiently complete for analysis, because they had been admitted after starting oncological treatment at another center.

This was a descriptive, cross-sectional study based on the medical records, radiology and anatomopathological findings and on the social data collected by our Social Services Department. The following data were analyzed: age, sex, nutritional status, origin, maternal educational level, total and per capita family income, histological subtype, tumor stage, serum lactate dehydrogenase (LDH) levels, duration of symptoms at time of diagnosis, primary tumor site, therapeutic scheme, response to treatment (relapse, death or remission) and length of follow-up.
In order to analyze possible associations between the probability of survival and the variables listed above, they were categorized and the patients allocated to groups (Table 1).

Nutritional status was assessed according to Z scores, using the National Center for Health Statistics growth curves as the standard, and defining patients as malnourished if any of their $z$ scores were further than -2 SD from the median of the reference group, as recommended by the World Health Organization (WHO). ${ }^{9}$

Anatomopathological assessments were performed by pathologists from the Pediatric Oncology Unit at IMIP, who were using the histological classification that was most widely accepted at that time: the Working Formulation, Revised European American Lymphoma Classification or the WHO classification. Despite of the classification employed, the patients were grouped into three subtypes: Burkitt's, lymphoblastic and large cell.

From 1999 onwards, immunohistochemical assays using the markers LCA, CD20, CD3, CD48 and ALK were used to diagnose NHL and determine the $B, T$, non-B and non- $T$ cell lines. ALK was used for those with anaplastic histology.

Staging was according to Murphy's classification (Saint Jude Children's Research Hospital). ${ }^{10}$

Serum LDH assays were performed within 24 hours of patient admission, being considered elevated when over 500 UI/dL (International Units per deciliter).

The therapeutic regimen was prescribed depending on histological typing and/or immunophenotype of the lymphoma and on the period during which the patient was admitted. Burkitt's and large B-cell lymphomas and/or those where the primary site was abdominal were treated with a chemotherapy protocol based on the LMB-89. ${ }^{11}$ With the aim of reducing toxicity related to the intensity of the chemotherapy regimen, from 1995 to 1997 a modified LMB-89 protocol was employed, with the following changes to the original protocol:

- Reduction of methotrexate dose to $1 \mathrm{~g} / \mathrm{m}^{2}$ in groups $B$ and $\mathrm{C}$.

- No cyclophosphamide dosage to be scaled up above $500 \mathrm{mg} / \mathrm{m}^{2} /$ day during COPADM courses.

- Substitution of the chemotherapy cycle known as CYVE by CYM, during consolidation of branch $\mathrm{C}$ of the protocol.

A therapeutic protocol based on the Total XIIIB-SJCRH was used for lymphoblastic lymphomas or large cell lymphomas of $\mathrm{T}$ cells and/or where the primary site was not abdominal. ${ }^{12}$

Treatment based on the LSA2L2 protocol ${ }^{13}$ was used for patients admitted during the first year of the service's operations, before the protocols described above were adopted. 
Table 1 - Overall and relative frequencies of the study variables, categorized for the purposes of survival analysis in patients with non-Hodgkin's lymphoma treated by the Pediatric Oncology Unit at the IMIP (Recife, Brazil, 1994-2003)

\section{Categorical clinical, epidemiological}

and socioeconomic variables

n

$\%$

$$
\begin{aligned}
& \text { Age (years) } \\
& \text { Up to } 5 \\
& >5 \text { to } 10 \\
& >10 \\
& \text { Sex } \\
& \text { Female } \\
& \text { Male }
\end{aligned}
$$

Nutritional status*

Well-nourished

Malnourished

Origin

Capital (Recife, PE)

Metropolitan region

Interior and other states

Maternal educational level ${ }^{\dagger}$

Illiterate

Up to 4th grade of primary education

More than 4th grade primary education

No information

Family income

Up to twice minimum wage

$>$ twice minimum wage

No information

Family income per capita

Up to $1 / 2$ minimum wage

$>1 / 2$ minimum wage

No information

Histological type

Burkitt's lymphoma

Lymphoblastic lymphoma

Large cell lymphoma

Stage $^{\ddagger}$

Localized

Advanced

$\mathrm{LDH}$

$\leq 500 \mathrm{UI} / \mathrm{dL}$

$>500 \mathrm{UI} / \mathrm{dL}$

Protocol

LMB-89

Modified LMB-89

Total XIII B SJCRH

LSA2L2

Duration of symptoms

Up to 30 days

$>30$ days

Primary site

Abdomen

Mediastinum

Peripheral lymph nodes

Others

\section{3}

37

20

32

78

20

11

79

14

28

30

38

45

24

41

51

17

42

86

11

13

10

100

73

36

55

34

11

10

48.2

33.6

18.2

29.1

70.9

77.3

18.2

10.0

71.8

12.7

25.5

27.2

34.6

40.9

21.8

37.3

46.4

15.4

38.2

78.2

10.0

11.8

9.1

90.9

67.0

33.0

50.0

30.9

10.0

9.1

60.9

39.1

$89 \quad 80.9$

$8 \quad 7.3$

$6 \quad 5.5$

$7 \quad 6.4$

IMIP = Instituto Materno-Infantil Professor Fernando Figueira; LDH = lactate dehydrogenase.

$* Z<-2$ SD in any of the three indices: weight/age, height/age and weight/height.

+ Highest grade passed.

‡ Localized (Murphy stages I and II) and advanced (Murphy stages III and IV). 
The Kaplan-Meier method was used to estimate global survival and disease-free survival. The following were considered as events: deaths for any reason or relapse of the disease. Patients who had not suffered any event until the day when the results were analyzed were censured. No losses of follow-up were observed. The log rank test was used for comparisons between groups. ${ }^{14}$

Deaths occurring within 30 days of admission were classed as early deaths. Improvement of the rate of early deaths was evaluated by means of tendency test (np trend test).

The level of significance used for the statistical tests was $5 \%(p<0.05)$ with $95 \%$ confidence intervals.

Data were input on a database created with Epi-Info, version 6, and statistical calculations were carried out using specialized software: SAS (Statistical Analysis System), version 8, SPSS (Statistical Package for the Social Sciences), version 11 and Stata 9.2.

This study was approved by the Human Research Ethics Committee at IMIP.

\section{Results}

During the period between May 1994 and May 2003, 110 patients with NHL were admitted to the IMIP Oncology Service.

Males predominated in a proportion of $2.4: 1$, and age varied from 21 months to 15 years, with a mean of $6.1 \pm 3.4$ years (median of 5 years).

Twenty-five patients were defined as malnourished, which was equivalent to $22.7 \%$ of our patients.

Only 31 patients (28.2\%) originated from the state capital (Recife) and the metropolitan region, with the remaining patients coming from the interior of the state or from other states.

Since the social form was only made routine in 1997, after the definitive implementation of the IMIP Pediatric Oncology Unit's Social Services Department, the data on maternal educational level, family income and family income per capita were not available for 38 (34.6\%), 41 (37.2\%) and 42 (38.2\%) patients, respectively.

With relation to the histological subtypes, Burkitt type $\mathrm{NHL}$ was observed to be predominant, affecting $78.2 \%$ (86) of the patients. Immunohistochemical studies were carried out for 33 of the $47(70.2 \%)$ patients admitted during the period from 1999 to 2003 , which is equivalent to $30 \%$ of the 110 patients studied. Of the 33 patients who underwent these tests, B cell line was confirmed $(C D 20+)$ in 25 patients $(75.7 \%)$, T cell line $(\mathrm{CD} 3+)$ in 6 patients $(18.2 \%)$ and non-B non-T (LCA+ with CD20- and CD3-) in 2 patients (6.1\%), both with anaplastic histology and ALK positive.

Only $10(9.1 \%)$ patients presented with localized disease (stages I and II) and 100 (90.9\%) presented with advanced disease (stages III or IV) and, of these, the majority, 95 $(86.4 \%)$ patients, had stage III lymphomas.

Elevated LDH levels (> $500 \mathrm{UI} / \mathrm{dL}$ ) were observed in only $36(33 \%)$ patients, and levels varied from 110 to $3,130 \mathrm{UI} / \mathrm{dL}$, with a mean of 504.41 $4476.86 \mathrm{UI} / \mathrm{dL}$ (median of $364 \mathrm{UI} / \mathrm{dL}$ ).

The duration of symptoms varied from 3 to 365 days, with a mean duration of $50.2 \pm 55.2$ days (median of 30 days). Patients whose complaints had lasted more than 30 days accounted for $39.1 \%$ (43) of cases.

Primary abdominal tumors were the most common among our patients, affecting $80.9 \%$ (89) of them.

The LMB-89 was the most used protocol, since Burkitt lymphomas and abdominal primaries predominated in this group of patients, and was given to $89(80.9 \%)$ patients; although $34(30.9 \%)$ patients were on the modified version with reduced toxicity.

The mean follow-up period was $3.31 \pm 2.83$ years, with a median of 2.8 years.

Ninety-four (85.4\%) of the 110 patients studied achieved remission and $16(14.6 \%)$ died within the first 30 days after diagnosis (early death), before their remission status was evaluated. Although it was not statistically significant (tendency test: $p=0.348$ ), it was observed that the rate of early deaths reduced over the years.

Of the patients who achieved remission, seven (7.4\%) have relapsed and 15 (16\%) died, 11 during first remission and four after a relapse.

The overall 2 and 5 year survival rates of our study were $73 \% \pm 4 \%$ and $70 \% \pm 4 \%$, respectively (Figure 1 ).

Disease-free survival was $70 \% \pm 4 \%$ at 2 years and $68 \% \pm 4 \%$, at 5 years. None of the clinical, epidemiological or socioeconomic variables exhibited a statistically significant association with global survival or disease-free survival ( $p>$ 0.05) (Table 2).

\section{Discussion}

Little data can be found in the Brazilian medical literature relating to the behavior of NHLs in the infant and juvenile population of our region. This study describes the epidemiological, clinical and socioeconomic characteristics of children with NHLs who were treated in a region where resources are limited.

We reviewed the medical records of 110 patients admitted with diagnosis of NHL to the Pediatric Oncology Unit at the IMIP during the period from May 1994 to May 2003. This was a larger patient sample than many others that have been described, both in Portuguese and other languages, that have reported the experience of a single institution in caring for and treating these patients.

The incidence of NHL increases uniformly with age and is rarely diagnosed before 2 years. ${ }^{3}$ In our study we observed 




Figure 1 - Global survival of non-Hodgkin's lymphoma patients, Kaplan-Meier method (Instituto Materno Infantil Professor Fernando Figueira, 1994-2003)

that NHL affects younger children than those described in foreign literature and this fact is compatible with other reports that have described other Brazilian experiences. ${ }^{6,7,15,16}$ The possibility of infectious etiology, principally related to the Epstein-Barr virus, ${ }^{4}$ being involved in the pathogenesis of Burkitt lymphomas may be a partial explanation for the emergence of this disease in younger patients in our region, since it is believed that populations in less privileged socioeconomic situations are exposed to infectious agents earlier.

With relation to sex, a predominance of male cases was observed, in a proportion of $2.4: 1$, which is similar to what is described in the literature. ${ }^{4}$
When we compared our rate of malnutrition with other studies involving Brazilian children with malignant neoplasms, we observed that our rate was lower than the others, ${ }^{15,17}$ which is a fact that warrants more profound analysis, since both studies used similar methodology to ours to define malnutrition.

The percentage of maternal illiteracy was lower in our group when compared with data from another research project carried out in our region, ${ }^{18}$ which makes us suppose that perhaps some children with $\mathrm{NHL}$, who were the children of illiterate mothers, may have had healthcare access difficulties, because of their mothers' scant understanding of the health-disease process, among other reasons.

Table 2 - Results of statistical tests for associations between overall survival and disease-free survival and the study variables, in patients with non-Hodgkin's lymphoma admitted to the Pediatric Oncology Unit at the IMIP (Recife, Brazil, 1994-2003)

\begin{tabular}{lcccc}
\hline & Global survival & & Disease-free survival \\
\hline Variable & Log rank & $\mathbf{p}$ & Log rank & p \\
\hline Sex & 0.33 & 0.5632 & 0.69 & 0.4042 \\
Age & 1.00 & 0.6059 & 1.07 & 0.5841 \\
Nutritional status & 0.47 & 0.4912 & 1.53 & 0.2159 \\
Origin & 1.99 & 0.3683 & 4.89 & 0.0867 \\
Family income & 2.68 & 0.1013 & 1.57 & 0.2096 \\
Family income per capita & 0.78 & 0.3766 & 0.18 & 0.6696 \\
Maternal educational & 4.51 & 0.1047 & 3.41 & 0.1819 \\
level & & & 0.81 & 0.8463 \\
Primary site & 0.81 & 0.8470 & 2.19 & 0.1385 \\
Duration of symptoms & 3.66 & 0.0557 & 2.15 & 0.1424 \\
Stage & 1.77 & 0.1832 & 0.17 & 0.9186 \\
Histological type & 0.28 & 0.8688 & 0.1047 & 0.1318 \\
LDH level & 2.63 & & & \\
\hline
\end{tabular}

IMIP = Instituto Materno-Infantil Professor Fernando Figueira; LDH = lactate dehydrogenase. 
The fact that more than $70 \%$ of our patients were sent to us from the interior of the state reflects the wide coverage of the IMIP as a regional reference hospital. This finding, together with the high percentage of patients with extremely low family incomes, reinforces the importance of nongovernmental institutions that provide socioeconomic support to the families of children with cancer and the implementation of an active and effective Social Service, integrated with the multidisciplinary team that cares for this group of patients. In the past, before these support services existed, an important cause of treatment failure was patients abandoning treatment, to a great extent as a result of the difficulties imposed by the distances involved and the underprivileged economic conditions observed in the majority of these patients' families, making the costs of treatment away from their localities of residence nonviable.

The duration of symptoms among our patients was, on average, 50 days, which is in agreement with results found by Pollock et al. ${ }^{19}$ in a study involving 2,665 patients with solid tumors. Considering the duration of symptoms of more than 30 days as delayed diagnosis, as it has previously been defined by other authors, ${ }^{20,21}$ we observed that around $40 \%$ of the patients on our study had a delayed diagnosis.

The high prevalence rates of advanced tumor stages in our series is probably related to, among other factors, the large number of patients with voluminous abdominal lymphomas, late diagnosis, and the predominance of primary mediastinal tumors within the lymphoblastic histological type, associated with a low frequency of NHL with more superficial primary sites, such as tumors of the head and neck and primary nodal disease, making it difficult to detect this pathology earlier in our children.

We found evidence of a high prevalence of NHL of the Burkitt histological subtype (78.2\%), when compared with American and European data. ${ }^{3}$ Sandlund et al. ${ }^{6}$ have previously made the same observation with relation to the distribution of histological types, reporting a frequency of $94 \%$ of Burkitt's lymphoma in children with NHL in our region.

This finding suggests that, in our children, Burkitt's lymphoma has a similar pattern of frequency to African Burkitt's lymphoma, ${ }^{5}$ although with clinical presentation that is essentially abdominal, similar to sporadic Burkitt lymphomas.

Evidence relating certain biological characteristics of Burkitt lymphomas, such as the association with the EpsteinBarr virus (EBV) and the point at which chromosome 8 is broken, supports the view that there are pathogenetically distinct subtypes of Burkitt's lymphoma in different regions of the world ${ }^{4}$ which could make us suppose that the patients in our study exhibit a type that is biologically distinct of the NHLs described in endemic (Africa) and sporadic variety (rest of world). However, in the light of current knowledge, this hypothesis cannot be confirmed, and further studies are needed into the subject in order that this question may be answered.

The survival of our patients approaches, although it remains inferior, to the results being currently presented by the major collaborative childhood cancer treatment groups, who report survival of around 80 to $90 \%$ for patients with $\mathrm{NHL}$ (Table 3).

However, we found that around $50 \%$ of our deaths (16 out of 31 deaths) occurred during the first 30 days after admission, being defined as early deaths that were frequently associated with comorbidities, such as metabolic, compressive and infectious complications, related to advanced disease stages. Excluding these deaths from our survival analysis, we observed a survival rate of around $80 \%$ at 2 years, close to the best results reported in the current period.

We therefore believe that efforts to reduce the rate of early deaths are essential, improving the clinical condition of these

Table 3 - Results of survival in non-Hodgkin's lymphoma in childhood from some of the major collaborative childhood cancer treatment groups

\begin{tabular}{|c|c|c|c|c|c|}
\hline Authors & $\mathbf{n}$ & Histology & Stages & \multicolumn{2}{|c|}{ Results } \\
\hline Reiter et al. ${ }^{22}$ & 302 & All & All & \multicolumn{2}{|c|}{ EFS 7a $80 \pm 2 \%$} \\
\hline \multirow[t]{2}{*}{ Link et al. ${ }^{23}$} & 340 & Non-lymphoblastic & Localized & \multicolumn{2}{|c|}{ EFS 5a $88 \%$} \\
\hline & & Lymphoblastic & Localized & \multicolumn{2}{|c|}{ EFS 5a 63\% } \\
\hline Amylon et al. ${ }^{24}$ & 195 & Lymphoblastic & Advanced & \multicolumn{2}{|c|}{ EFS 4a $78 \pm 5 \%$} \\
\hline Reiter et al. ${ }^{25}$ & 105 & Lymphoblastic & All & \multicolumn{2}{|c|}{ EFS 5a $90 \%$} \\
\hline Seidemann et al. ${ }^{26}$ & 89 & Anaplastic large cell & All & \multicolumn{2}{|c|}{ EFS $5 a$ a $76 \pm 5 \%$} \\
\hline Patte et al. ${ }^{11}$ & 561 & $\begin{array}{l}\text { Burkitt's and large } \\
\text { cell }\end{array}$ & All & EFS 5a $91 \%$ & GS 5a $92.5 \%$ \\
\hline Laver et al. 27 & 180 & Large cell & Advanced & EFS $4 a$ a $67.4 \pm 4.2 \%$ & GS $4 a$ a $80.1 \pm 3.6 \%$ \\
\hline
\end{tabular}

EFS = event-free survival; GS = global survival. 
children at admission, by means of procedures such as: diagnosis during earlier phases, improved hospital infrastructure and capacitation of health professionals.

The impact of such measures has already resulted in improved survival among our acute lymphoblastic leukemia patients, as Howard et al. ${ }^{28}$ have described, and maybe related to the decreasing in early death rate observed in this study over the 9 years of our analysis.

In relation to the attempt to identify prognostic factors, no statistically significant associations were demonstrated between the clinical, epidemiological and socioeconomic variables and either global survival or disease-free survival in our study, which may be due to insufficient sample size or may be related to the important socioeconomic support that the families of our patients are given by a nongovernmental institution, which has been cited above as one possible cause of the improvements in survival among children with cancer in countries with limited resources. ${ }^{28}$

Finally, we suggest that further studies be carried out in order to better define prognostic factors and in order to elucidate etiopathogenic factors that could be associated with the differences in the form of presentation of NHLs among children in our region.

\section{Acknowledgements}

We are grateful to Prof. José Natal Figueroa, Professor of Biostatistics at the IMIP, for his dedicated help with the statistical analysis.

We would also like to thank Dr Raul Ribeiro (International Outreach Program, St. Jude Children's Research Hospital), Dr Scott Howard (International Outreach Program, St. Jude Children's Research Hospital), Mr. Hélio Monteiro (Pediatric Oncology Department Library, IMIP) and Dr. Beatriz Camargo (Doctorate in Medicine from the Medical Faculty of USP), for helping with designing the project and writing the article.

\section{References}

1. Brasil, Ministério da Saúde. Indicadores de mortalidade. Brasília: Ministério da saúde; 2002. http://tabnet.datasus.gov.br/cgi/ deftohtm.exe?idb2002/c04.def. Access: 22.06.2007.

2. Greenlee RT, Hill-Harmon MB, Murray T, Thun M. Cancer statistics, 2001. CA Cancer J Clin. 2001;51:15-36.

3. Sandlund JT, Downing JR, Crist WM. Non-Hodgkin's lymphoma in childhood. N Engl J Med. 1996;334:1238-48.

4. Gutiérrez MI, Bhatia K, Barriga F, Diez B, Muriel FS, de Andreas $M L$, et al. Molecular epidemiology of Burkitt's Iymphoma from South America: differences in breakpoint location and EpsteinBarr virus association from tumors in other world regions. Blood. $1992 ; 79: 3261-6$

5. Magrath IT. African Burkitt's lymphoma. History, biology, clinical features, and treatment. Am J Pediatr Hematol Oncol. 1991; $13: 222-46$
6. Sandlund JT, Fonseca T, Leimig T, Verissimo L, Ribeiro R, Lira V, et al. Predominance and characteristics of Burkitt lymphoma among children with non-Hodgkin Iymphoma in northeastern Brazil. Leukemia. 1997;11:743-56.

7. Bittencourt AL, Mendonça N, Cordeiro CO, Nunes CA, Bittencourt AR. Linfoma maligno não-Hodgkin na infância: estudo clínicopatológico de 70 casos. J Pediatr (Rio J). 1987;62:259-66.

8. Viana MB, Fernandes RA, de Carvalho RI, Murao M. Low socioeconomic status is a strong independent predictor of relapse in childhood acute lymphoblastic leukemia. Int J Cancer Suppl. 1998;11:56-61.

9. Use and interpretation of anthropometric indicators of nutritional status. WHO Working Group. Bull World Health Organ. 1986; 64:929-41.

10. Murphy SB. Classification, staging and end results of treatment of childhood non-Hodgkin's lymphomas: dissimilarities from lymphomas in adults. Semin Oncol. 1980;7:332-9.

11. Patte C, Auperin A, Michon J, Behrendt H, Leverger G, Frappaz D, et al. The Société Française d'Oncologie Pédiatrique LMB89 protocol: highly effective multiagent chemotherapy tailored to the tumor burden and initial response in 561 unselected children with B-cell lymphoma and L3 leukemia. Blood. 2001;97:3370-9.

12. Pui CH, Sandlund JT, Pei D, Campana D, Rivera GK, Ribeiro RC, et al. Improved outcome for children with acute lymphoblastic leukemia: results of Total Therapy Study XIIIB at St Jude Children's Research Hospital. Blood. 2004;104:2690-6.

13. Wollner N, Exelby PR, Lieberman PH. Non-Hodgkin's lymphoma in children: a progress report on the original patients treated with LSA2-L2 protocol. Cancer. 1979;44:1990-9.

14. Bustamante-Texeira MT, Faerstein E, Latorre MR. Técnicas de análise de sobrevida. Cad Saude Publica. 2002;18:579-94

15. Alvim RC, Mesquita CJ, Cerqueira TA, Viana MB. Evolução dos linfomas não-Hodgkin na criança: análise do estado nutricional e de outros fatores prognósticos. J Pediatr (Rio J). 1996;72:40010.

16. Klumb CE, Schramm MT, De Resende LM, Carriço MK, Coelho AM, de Meis EM, et al. Treatment of children with B-cell nonHodgkin's lymphoma in developing countries: the experience of a single center in Brazil. J Pediatr Hematol Oncol. 2004; 26:462-8.

17. Pedrosa F, Bonilla M, Liu A, Smith K, Davis D, Ribeiro RC, et al. Effect of malnutrition at the time of diagnosis on the survival of children treated for cancer in El Salvador and northern Brazil. J Pediatr Hematol Oncol. 2000;22:502-5.

18. Batista Filho M, Romani AS, organizadores. Alimentação, nutrição e saúde no estado de Pernambuco: espacialização e fatores socioeconômicos. Recife: IMIP; 2002.

19. Pollock BH, Krischer JP, Vietti TJ. Interval between symptom onset and diagnosis of pediatric solid tumors. J Pediatr. 1991; 119:725-32.

20. Fajardo-Gutiérrez A, Sandoval-Mex AM, Mejía-Aranguré JM, Rendón-Macías ME, Martínez-García Mdel C. Clinical and social factors that affect the time to diagnosis of Mexican children with cancer. Med Pediatr Oncol. 2002;39:25-31.

21. Rodrigues KES. Estudo dos fatores que influenciam o atraso do diagnóstico das neoplasias malignas pediátricas dos pacientes admitidos no Hospital do Câncer de São Paulo no período de 1991 a 2002 [dissertação]. São Paulo: Fundação Antônio Prudente; 2002. 
22. Reiter A, Schrappe M, Parwaresch R, Henze G, MullerWeihrich S, Sauter S, et al. Non-Hodgkin's lymphomas of childhood and adolescence: results of a treatment stratified for biologic subtypes and stage - a report of Berlin-FrankfurtMünster Group. J Clin Oncol. 1995;13:359-72.

23. Link MP, Shuster J], Donaldson SS, Berard CW, Murphy SB. Treatment of children and young adults with early-stage nonHodgkin's lymphoma. N Engl J Med. 1997;337:1259-66.

24. Amylon MD, Shuster J, Pullen J, Berard C, Link MP, Wharam M, et al. Intensive high-dose asparaginase consolidation improves survival for pediatric patients with $\mathrm{T}$ cell acute lymphoblastic leukemia and advanced stage lymphoblastic lymphoma: a Pediatric Oncology Group study. Leukemia. 1999;13:335-42.

25. Reiter A, Schrappe M, Ludwig WD, Tiemann M, Parwaresch R, Zimmermann $M$, et al. Intensive ALL-type therapy without local radiotherapy provides a $90 \%$ event-free survival for children with T-cell Iymphoblastic Iymphoma: a BFM group report. Blood. 2000;95:416-21.

26. Seidemann K, Tiemann M, Schrappe M, Yakisan E, Simonitsch I, Janka-Schaub G, et al. Short-pulse B-non-Hodgkin lymphomatype chemotherapy is efficacious treatment for pediatric anaplastic large cell lymphoma: a report of the Berlin-FrankfurtMunster Group Trial NHL-BFM 90. Blood. 2001;97:3699-706.
27. Laver JH, Kraveka JM, Hutchison RE, Chang M, Kepner J, Schwenn M, et al. Advanced-stage large-cell lymphoma in children and adolescents: results of a randomized trial incorporating intermediate-dose methotrexate and high-dose cytarabine in the maintenance phase of the APO regimen: a Pediatric Oncology Group phase III trial. J Clin Oncol. 2005; 23:541-7.

28. Howard SC, Pedrosa M, Lins M, Pedrosa A, Pui CH, Ribeiro RC, et al. Establishment of a pediatric oncology program and outcomes of childhood acute lymphoblastic leukemia in a resource-poor area. JAMA. 2004;291:2471-5.

Correspondence:

Márcia F. Pedrosa

Rua Joaquim Inácio, 187, Ilha do Leite

CEP 500070-270 - Recife, PE - Brazil

Tel.: +55 (81) 2101.8100

Fax: +55 (81) 3421.2424

E-mail: marcia.pedrosa@cehope.com.br 